\title{
BERCHEX, Joaquín y CORELL, Vicente, Catálogo de diseños de arquitectura de la Real Academia de Bellas Artes de San Carlos de Valencia. 1768-1846. 430 p. il. b. y n., $32 \times 5 \mathrm{~cm}$.
}

Por R. N. M.

La idea de presentar un catálogo de diseños arquitectónicos de la Real Academia de San Carlos / 1768-1846), realizados en el período en que ésta no sólo expedía los títulos de arquitecto, sino también ejercía el control de la arquitectura pública; supone la posibilidad de relacionarlos, tanto con el movimiento ilustrado, como con su antecedente barroco, e incluso que el propio aporte icónico, al seleccionarse, pueda adquirir por sí solo rasgos de discurso.

Efectivamente, las seicientas cuarenta y tres ilustraciones no sólo permiten detectar la evolución arquitectónica del neoclasicismo valenciano, sino, sobre todo, insinuar el modo en que se orienta en Valencia "la restauración de las artesn, tanto en el sentido humanista de Jovellanos, como en el arqueológico de Mengs.

Así, la labor de Berchez y Corell, al recrear mediante la ordenación de los diseños, el desarrollo de la institución: premios, concursos, títulos, grados, etc., permite que, a través de ellos, nos acerquemos a la realidad intelectual y social de la Academia (se ofrecen también ciento catorce someras biografías de los arquitectos representados), y, por consiguiente, que observemos la doble direccionalidad del movimiento: concepción de la belleza y visión del Renacimiento, de tal modo que la arquitectura se nos aparece como lo que fue para los ilustrados, un hecho de cultura.

Por último, una cuidada selección de índices y bibliografía básica, contribuyen a completar un trabajo que habrá de servir de revulsivo a los estudios sobre el tema en la generalidad del territorio.

En definitiva, una obra de indispensable consulta en el conjunto del movimiento ilustrado valenciano. 